\title{
Pharmacokinetics of Panasenoside in Rats and Tissue Distribution in Mice by Ultra-Performance Liquid Chromatography Tandem Mass Spectrometry
}

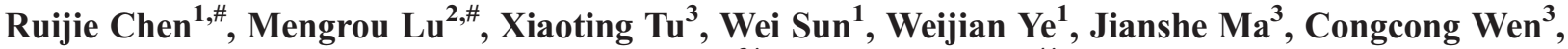 \\ Xianqin Wang ${ }^{3^{*}}$ and Peiwu Geng ${ }^{4 *}$ \\ ${ }^{1}$ The Second Affiliated Hospital and Yuying Children's Hospital, Wenzhou Medical University, Wenzhou 325000, China \\ ${ }^{2}$ Cellular Biomedicine Group (Shanghai), Inc., 333 Guiping Road, Xuhui, Shanghai 200233, China \\ ${ }^{3}$ Analytical and Testing Center, School of Pharmaceutical Sciences, Wenzhou Medical University, Wenzhou 325035, China \\ ${ }^{4}$ The Laboratory of Clinical Pharmacy, The People's Hospital of Lishui, Lishui 323000, China
}

Received: 21 November 2017; accepted: 28 December 2017

\begin{abstract}
We developed an ultra-performance liquid chromatography tandem mass spectrometry (UPLC-MS/MS) method for quantification of panasenoside pharmacokinetics in rat plasma and tissue distribution in mouse. Twelve male SpragueDawley rats were used for pharmacokinetics after intravenous (2 or $10 \mathrm{mg} / \mathrm{kg}$ ) administration of panasenoside, six rats for each dose. Thirty mice were randomly divided into six groups (five mice for each group, one group for each time point) and received $20 \mathrm{mg} / \mathrm{kg}$ of panasenoside by intraperitoneal administration. Calibration plots were in the range of $2-2000 \mathrm{ng} / \mathrm{mL}$ for panasenoside in rat plasma and $2-3000 \mathrm{ng} / \mathrm{mL}$ in mouse tissues. The relative standard deviation (RSD) of inter-day and intra-day precision was less than $14 \%$. The accuracy was between $89.6 \%$ and $110.0 \%$. The $\mathrm{AUC}_{(0-t)}$ was $160.8 \pm 13.0$ and $404.9 \pm 78.0 \mathrm{ng} / \mathrm{mL} * \mathrm{~h}$, and $t_{1 / 2}$ of $3.2 \pm 1.2$ and $4.6 \pm 1.7 \mathrm{~h}, \mathrm{CL}$ (clearance) of $10.0 \pm 2.0$, and $21.4 \pm 2.0 \mathrm{~L} / \mathrm{h} / \mathrm{kg}$ after intravenous administration $2 \mathrm{mg} / \mathrm{kg}$ and $10 \mathrm{mg} / \mathrm{kg}$ of panasenoside, respectively. The tissue distribution results indicated that the panasenoside diffuses rapidly and widely into major organs. The level of panasenoside was highest in mouse liver, followed by kidney, lung, and spleen. The overwhelming accumulation in liver indicated that liver was responsible for the extensive metabolism.
\end{abstract}

Keywords: Mouse, rat, UPLC-MS/MS, panasenoside, tissue distribution

\section{Introduction}

Radix Ginseng has a long history in Asia as a precious traditional medicine for prevention and treatment of a wide range of diseases since ancient times [1]. The major active ingredients of Radix Ginseng are ginsenosides that consist of a series of derivatives of triterpene dammarane [2]. Recently, studies indicate that multiple components of ginsenosides such as saponins, flavonoid, and polyacetylenes are the active compounds in Radix Ginseng [3], and their pharmacological activities contribute to antioxidizing, antibacterial, neuroprotective, antitumor, hypotensive, sedative, analgesic, and anti-stress effects [4,5]. Panasenoside is one of the major flavonoids in the Radix Ginseng.

Though Radix Ginseng has been considered as an herbal therapeutic for centuries in Asia, people have never stopped questioning its treatment effects. This is largely a problem of traditional Asian medical system which seldom presents the mechanism or pharmacological evidence in an intuitive manner recognized by modern biology, which calls for accurate quantitation of the active ingredients of the plant. Therefore, developing a precise bioanalytical method for panasenoside is in urgent need.

Despite the mere report of determining panasenoside in Folium Ginseng and Radix Ginseng extracts [4], Qian et al. developed a rapid pressurized liquid extraction (PLE) and highperformance liquid chromatography coupled with diode array detection and mass spectrometry (HPLC-DAD-MS) method for the simultaneous determination of one flavonoid (panasenoside), nine saponins (ginsenoside $\mathrm{Rg} 1, \mathrm{Re}, \mathrm{Rf}, \mathrm{Rg} 2, \mathrm{Rb} 1, \mathrm{Rc}$, $\mathrm{Rb} 2, \mathrm{Rb} 3$, and $\mathrm{Rd}$ ), and two polyacetylenes (panaxydol and panaxynol) in Folium Ginseng and Radix Ginseng, the Prevail

\footnotetext{
* Author for correspondence: lankywang@163.com gengpeiwu@163.com

\# These two authors contributed equal to this work.
}

C18 rocket column $(33 \mathrm{~mm} \times 7 \mathrm{~mm}, 3.0 \mu \mathrm{m})$ and gradient elution were used during the analysis, the total run time needed $30 \mathrm{~min}$, the limit of detection (LOD) and limit of quantification (LOQ) of panasenoside were 0.3 and $0.8 \mu \mathrm{g} / \mathrm{mL}$ [4].

There is no effective bioanalytical method available to quantify panasenoside in biological samples to date. Compared to liquid chromatography tandem mass spectrometry (LC-MS/MS), ultraperformance liquid chromatography (UPLC)-MS/MS is more sensitive and faster, offering significant advantages in the investigation of pharmacokinetics of chemical drugs $[6,7]$. In our study, we developed a sensitive UPLC-MS/MS method for quantification of panasenoside in rat plasma and mouse tissues (heart, liver, spleen, lung, kidney, and brain), which only needs 4 min for each sample, and then further applied the method to the pharmacokinetic analysis after intravenous administration in rat plasma and tissue distribution in mouse.

\section{Experimental}

Chemicals. Panasenoside (purity $>98 \%$, Figure 1a) and naringin (IS (internal standard), purity $>98 \%$, Figure 1b) were obtained from Chengdu Mansite Pharmaceutical Co. Ltd. (Chengdu, China). Chromatography grade methanol, acetonitrile, and formic acid were obtained from Merck Company (Darmstadt, Germany). Ultrapure water (resistance $>18 \mathrm{M} \Omega$ ) was prepared by Milli-Q purification system (Bedford, USA).

Instrumentation and Conditions. XEVO TQS-micro triple quadrupole mass spectrometer and ACQUITY I-Class UPLC, equipped with electrospray ionization (ESI) interface, were from Waters Corp. (Milford, MA, USA). Masslynx 4.1 software (Milford, MA, USA) was used for instrument control and data acquisition.

This is an open-access article distributed under the terms of the Creative Commons Attribution-NonCommercial 4.0 International License (https://creativecommons.org/licenses/by-nc/4.0/), which permits unrestricted use, distribution, and reproduction in any medium for non-commercial purposes, provided the original author and source are credited, a link to the CC License is provided, and changes - if any - are indicated. 
<smiles>C[C@@H]1O[C@H](O[C@H]2[C@@H](O)[C@H](O)[C@@H](O)[C@H](O)[C@H]2O)[C@H](Oc2cc(O)c3c(c2)OC(c2ccc(O)cc2)CC3=O)O[C@H](CO)[C@@H]1O</smiles>

Figure 1. Chemical structure of panasenoside (A) and naringin (IS, B)

Panasenoside and IS were chromatographic separation achieved on a UPLC BEH C18 column $(2.1 \mathrm{~mm} \times 50 \mathrm{~mm}$, $1.7 \mu \mathrm{m})$. The mobile phase consisted of $0.1 \%$ formic acid and acetonitrile, the flow rate was set at $0.4 \mathrm{~mL} / \mathrm{min}$, and column temperature was set at $40{ }^{\circ} \mathrm{C}$. The gradient elution condition was as follows: $0-0.2 \mathrm{~min}$, acetonitrile $10 \% ; 0.2-1.5 \mathrm{~min}$, acetonitrile $10 \%-80 \%$; $1.5-2.0 \mathrm{~min}$, acetonitrile $80 \% ; 2.0-2.5 \mathrm{~min}$, acetonitrile $80 \%-10 \%$; and $2.5-3.5 \mathrm{~min}$, acetonitrile $10 \%$.

The mass parameters were listed as follows: capillary voltage of $2.0 \mathrm{kV}$, desolvation temperature of $400{ }^{\circ} \mathrm{C}$, desolvation gas (nitrogen) of $800 \mathrm{~L} / \mathrm{h}$, and cone gas of $50 \mathrm{~L} / \mathrm{h}$. MRM modes of $\mathrm{m} / \mathrm{z} 609.2 \rightarrow 284.1$ for panasenoside and $\mathrm{m} / \mathrm{z} 579.2 \rightarrow 271.1$ for IS were used for quantitative analysis in negative mode (Figure 2).

Calibration Standards. The stock solutions of panasenoside $(1.0 \mathrm{mg} / \mathrm{mL})$ were prepared in methanol. The stock solutions of IS $(0.5 \mathrm{mg} / \mathrm{mL})$ were prepared in methanol. The $0.5 \mu \mathrm{g} / \mathrm{mL}$ IS working solution was prepared from the stock solution by dilution with methanol. The stock solutions and working solution were stored at $4{ }^{\circ} \mathrm{C}$.

Panasenoside calibration standards were prepared by spiking working solutions of incremental concentration into blank rat plasma. Calibration plots were offset to range between 2 and $2000 \mathrm{ng} / \mathrm{mL}$ for panasenoside in rat plasma $(2,6,20,100$, 200, 400, 800, 1500, and $2000 \mathrm{ng} / \mathrm{mL}$ ) and between 2 and $3000 \mathrm{ng} / \mathrm{mL}$ in mouse tissue $(2,10,50,200,500,1000,2000$, and $3000 \mathrm{ng} / \mathrm{mL}$ ), each by adding $5 \mu \mathrm{L}$ of the appropriate working solution to $50 \mu \mathrm{L}$ of blank rat plasma or $50 \mathrm{mg}$ of mouse tissue, and then mixed by brief vortexing. Quality-control (QC) samples were prepared in three concentrations of rat plasma (3, 250, and $1800 \mathrm{ng} / \mathrm{mL}$ ) or mouse liver (3, 400, and $2500 \mathrm{ng} / \mathrm{mL}$ ). The proteins of calibration standards and QC samples were precipitated by methanol before UPLC-MS/MS analysis.

Sample Preparation. The $5 \mu \mathrm{L}$ IS working solution $(0.5 \mu \mathrm{g} / \mathrm{mL})$ was added to $50 \mu \mathrm{L}$ plasma sample in a $1.5 \mathrm{~mL}$ centrifuge tube, and $150 \mu \mathrm{L}$ methanol was added, then vortexmixed for $1.0 \mathrm{~min}$, and centrifuged at $14,900 \mathrm{~g}$ for $10 \mathrm{~min} ; 2 \mu \mathrm{L}$ of the supernatant was injected into the UPLC-MS/MS system.

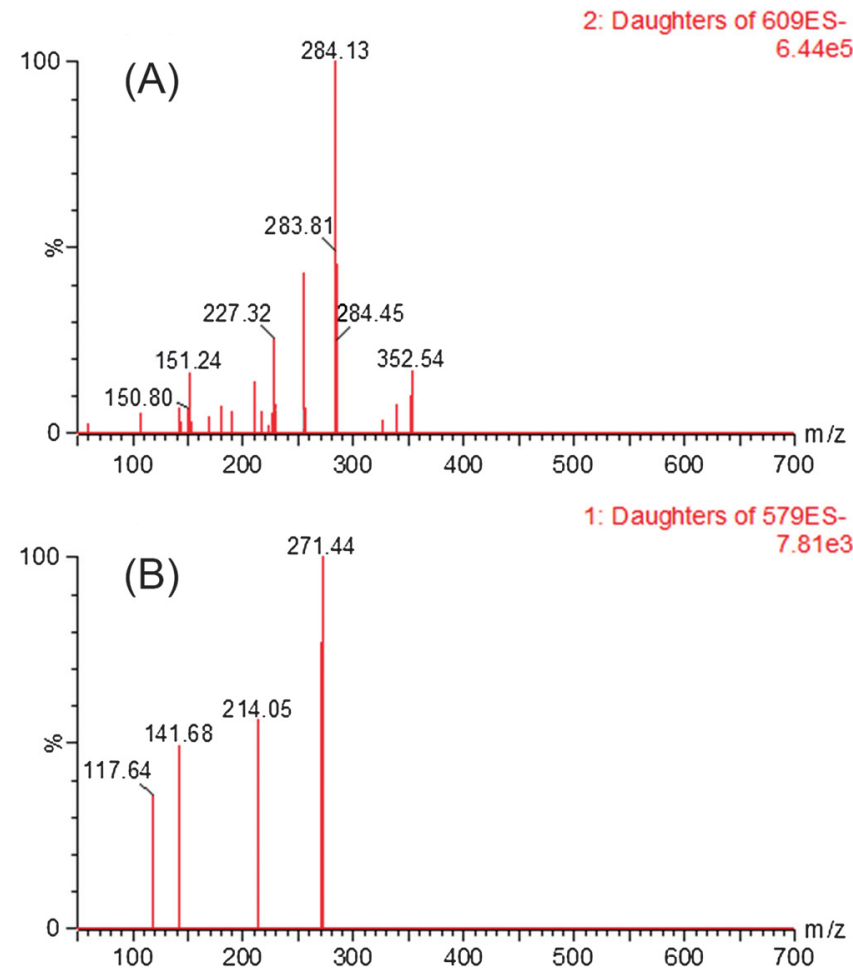

Figure 2. Mass spectrum of panasenoside (A) and naringin (IS, B)

The mouse tissues (heart, liver, spleen, lung, kidney, and brain) were respectively weighed accurately $50 \mathrm{mg}$ and placed in $1.5 \mathrm{~mL}$ centrifuge tubes, and then filled with $200 \mu \mathrm{L}$ methanol and $5 \mu \mathrm{L}$ IS working solution $(0.5 \mu \mathrm{g} / \mathrm{mL})$. The mixtures were stored at $-80{ }^{\circ} \mathrm{C}$ for $10 \mathrm{~min}$ and then grinded for $3 \mathrm{~min}$ by SCIENTZ-48 Tissue Grinder (64 Hz and $1800 \mathrm{r} / \mathrm{s})$. The tubes were vortex-mixed for $1.0 \mathrm{~min}$ and centrifuged at $14,900 \mathrm{~g}$ for $10 \mathrm{~min}$, and $2 \mu \mathrm{L}$ of the supernatant was injected into the UPLC-MS/MS system.

Method Validation. Method validation was conducted according to the guidelines set by the European Medicines Agency (EMA). Validation runs were conducted on three consecutive days, with each run consisted of six replicates of QC samples and one set of calibration standards [8-10].

The selectivity of the method was evaluated by analyzing six lots of different sources of blank rat plasma or mouse liver, blank plasma or mouse liver spiked with panasenoside and IS, and a rat plasma sample or a mouse liver sample.

Calibration curves were obtained by analyzing spiked calibration samples on three separate days. Peak area ratios of panasenoside-to-IS were plotted against panasenoside concentrations. Standard curves were well fitted to the equations by linear regression, with a weighting factor of the reciprocal of the concentration $(1 / x)$ in the concentration range of $2-2000 \mathrm{ng} / \mathrm{mL}$ for rat plasma and 2-3000 ng/mL for mouse tissues. The lower limit of quantitation (LLOQ) was defined as the lowest concentration on the calibration curves.

To evaluate the matrix effect, blank rat plasma was extracted and then spiked with the analyte at 3,250, and $1800 \mathrm{ng} / \mathrm{mL}$ $(n=6)$, and blank mouse tissues (heart, liver, spleen, lung, kidney, and brain) were extracted and then spiked with the analyte at 3,400 , and $2500 \mathrm{ng} / \mathrm{mL}$. The corresponding peak areas were then compared to those of neat standard solutions at equivalent concentrations, and this peak area ratio is defined as the matrix effect. The matrix effect of the IS was evaluated at a concentration of $50 \mathrm{ng} / \mathrm{mL}$ in the similar manner.

Accuracy and precision were evaluated by the determination of QC samples at three concentration levels (3, 250, and $1800 \mathrm{ng} / \mathrm{mL}$ for rat plasma; 3, 400, and $2500 \mathrm{ng} / \mathrm{mL}$ for 
mouse tissue) in six replicates over three validation. The precision is expressed by relative standard deviation (RSD).

The recovery of panasenoside was evaluated by comparing the peak area of extracted QC samples with those of reference QC solutions reconstituted in blank plasma or blank mouse tissue extracts $(n=6)$. The recovery of the IS was determined in the same way $[11,12]$.

Stability of panasenoside in rat plasma and mouse liver was evaluated by analyzing three replicates of plasma samples $(3,250$, and $1800 \mathrm{ng} / \mathrm{mL}$ ) and liver sample (3, 400, and $2500 \mathrm{ng} / \mathrm{mL}$ ) that are exposed to different conditions. These results were compared with that of freshly prepared plasma or liver samples. Short-term stability was determined after the exposure of the spiked samples to room temperature for $2 \mathrm{~h}$ and the ready-toinject samples (after protein precipitation) in the HPLC autosampler at room temperature for $12 \mathrm{~h}$. Freeze-thaw stability was evaluated after three complete freeze-thaw cycles $(-20$ to $25^{\circ} \mathrm{C}$ ) on consecutive days. Long-term stability was assessed after storage of the standard spiked plasma samples at $-20{ }^{\circ} \mathrm{C}$ for 20 days. The stability of the IS $(50 \mathrm{ng} / \mathrm{mL})$ was also evaluated with the similar method $[13,14]$.

Pharmacokinetic Study. All twelve male Sprague-Dawley rats (200-220 g) were obtained from the Laboratory Animal Center of Wenzhou Medical University. Diet was prohibited for $12 \mathrm{~h}$ before the experiment while water was freely available. Blood samples $(0.2 \mathrm{~mL})$ were collected from the tail vein into heparinized $1.5 \mathrm{~mL}$ centrifuge tubes at $0.0333,0.25,0.5,1,2,3$, 4,6 , and $8 \mathrm{~h}$ after intravenous ( 2 or $10 \mathrm{mg} / \mathrm{kg}$ ) administration of panasenoside, six rats for each dose, and then centrifuged at $3000 \mathrm{~g}$ for $10 \mathrm{~min}$. The freshly obtained plasma was stored at $-20{ }^{\circ} \mathrm{C}$ until analysis. Plasma panasenoside concentration versus time was analyzed by version 2.0 DAS (Drug and Statistics) software (China Pharmaceutical University).

Tissue Distribution Study. Thirty mice were randomly divided into six groups (five mice for each group, one group for each time point) and received $20 \mathrm{mg} / \mathrm{kg}$ of panasenoside by intraperitoneal administration. The mice were euthanized by decapitation at 0 (blank group), $0.25,0.5,2,4$, and $6 \mathrm{~h}$ after given panasenoside. Tissues were removed and washed with saline then stored at $-20^{\circ} \mathrm{C}$.

\section{Results and Discussion}

Method Development. In comparison with conventional analytical techniques, UPLC-MS/MS has been proven to improve sensitivity, selectivity, and specificity in determination of the active compound of herbal drug in biological samples. Consequently, we established a UPLC-MS/MS method for the determination of panasenoside in rat plasma and mouse tissue, and then successfully applied the method to the pharmacokinetic study in rats and tissue distribution study in mice.

The feasibility of ESI in negative and positive ion modes of detection was evaluated [15-17], and ESI with negative ion detection resulted in a better signal-to-noise ratio for both panasenoside and IS.

The mobile phase was also optimized for UPLC-MS/MS. We explored the mobile phase with methanol, acetonitrile, water, $0.1 \%$ formic acid, and $0.1 \%$ ammonia in combinations and concluded with acetonitrile- $0.1 \%$ formic acid to be the optimal choice as this combination provided relatively clean chromatographic peaks and acceptable sensitivity. The gradient elution mode was chosen in our work for its thorough cleaning of the impurity in the column and the protection of the chromatographic system [18-21].

UPLC-MS/MS analysis requires a rapid, simple, and convenient sample treatment method with acceptable recovery and matrix effect [22-26]. We tried plasma $(50 \mu \mathrm{L})$ with acetonitrile, methanol, ethyl acetate, and ether in our study. The result indicated that methanol has the highest extraction efficiency with acceptable matrix effect, and thus, methanol was used in protein precipitation for plasma and tissues in this work.

We further investigated the performance of naringin as IS. As naringin and panasenoside exhibited similar chromatographic retentions and both were suitable for analysis in the negative ESI interface, naringin was used as IS in our study.

Selectivity and Matrix Effect. Figure 3 showed typical chromatograms of a blank plasma sample, a blank plasma sample spiked with panasenoside and IS, and a plasma sample from a rat after intravenous administration of panasenoside. Figure 4 showed typical chromatograms of a blank mouse liver, a blank mouse liver sample spiked with panasenoside and IS, and a mouse liver sample after intraperitoneal administration of panasenoside in mouse. There were no interfering endogenous substances observed at the retention time of the panasenoside and IS.

The matrix effect of panasenoside at concentrations of 3, 250, and $1800 \mathrm{ng} / \mathrm{mL}$ in rat plasma was measured to be between $91.7 \%$ and $94.5 \%(n=6)$ and at 3, 400, and $2500 \mathrm{ng} / \mathrm{mL}$ in mouse tissues was measured to be between $85.1 \%$ and $98.8 \%$ $(n=6)$ (Table 1). The matrix effect of IS $(50 \mathrm{ng} / \mathrm{mL})$ was measured to be $95.6 \%(n=6)$ in rat plasma and $90.4 \%(n=6)$ in mouse liver. The result of matrix effect from plasma and mouse tissues was acceptable.

Calibration Curve and Sensitivity. Linear regressions were fitted over the $2-2000 \mathrm{ng} / \mathrm{mL}$ for panasenoside in rat plasma. The calibration curve was as follows: $y=0.005037 x-0.007529$, $r=0.9985$, where $y$ represents the ratios of panasenoside peak area to that of IS and $x$ represents the plasma concentration. The
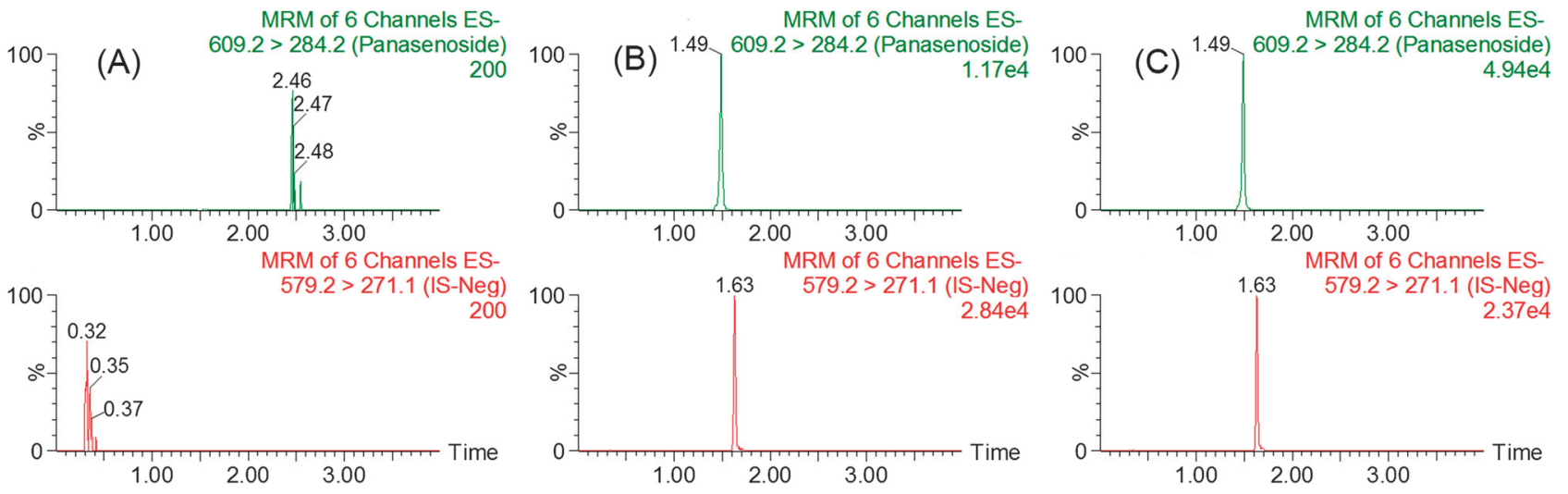

Figure 3. Representative UPLC-MS/MS chromatograms of panasenoside and naringin (IS) in rat plasma. A, blank plasma; B, blank plasma spiked with panasenoside $(20 \mathrm{ng} / \mathrm{mL})$ and IS (50 ng/mL); C, a rat plasma sample after intravenous administration of single dosage $2 \mathrm{mg} / \mathrm{kg}$ panasenoside 

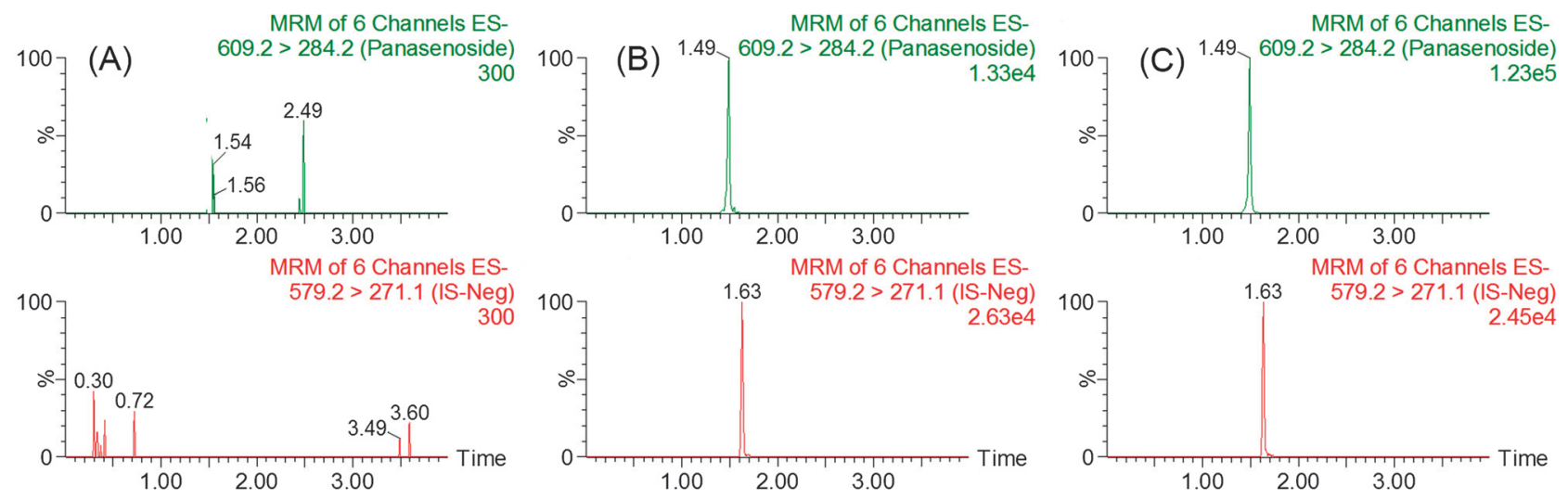

Figure 4. Representative UPLC-MS/MS chromatograms of panasenoside and naringin (IS) in mouse liver. A, blank mouse liver; B, blank mouse liver spiked with panasenoside ( $20 \mathrm{ng} / \mathrm{mL}$ ) and IS (50 ng/mL); C, a mouse liver sample after intraperitoneal administration of $20 \mathrm{mg} / \mathrm{kg}$ panasenoside in mouse

Table 1. Precision, accuracy, matrix effect, and recovery for panasenoside of QC sample in rat plasma and mouse liver $(n=6)$

\begin{tabular}{|c|c|c|c|c|c|c|c|}
\hline \multirow[t]{2}{*}{ Matrix } & \multirow{2}{*}{$\begin{array}{c}\text { Concentration } \\
(\mathrm{ng} / \mathrm{mL})\end{array}$} & \multicolumn{2}{|c|}{ Precision $(\mathrm{CV} \%)$} & \multicolumn{2}{|c|}{ Accuracy (\%) } & \multirow{2}{*}{$\begin{array}{c}\text { Matrix } \\
\text { effect }\end{array}$} & \multirow[t]{2}{*}{ Recovery } \\
\hline & & Intra-day & Inter-day & Intra-day & $\overline{\text { Inter-day }}$ & & \\
\hline \multirow[t]{4}{*}{ Plasma } & 3 & 9.6 & 11.4 & 104.2 & 94.0 & 91.7 & 86.7 \\
\hline & 250 & 6.7 & 7.3 & 98.2 & 95.6 & 94.5 & 94.6 \\
\hline & 1800 & 5.6 & 4.6 & 96.3 & 102.0 & 92.3 & 84.2 \\
\hline & 3 & 10.6 & 9.4 & 100.0 & 95.2 & 86.0 & 84.3 \\
\hline \multirow[t]{4}{*}{ Liver } & 400 & 6.2 & 8.8 & 105.1 & 103.7 & 85.1 & 88.2 \\
\hline & 2500 & 8.0 & 4.0 & 98.5 & 94.6 & 87.8 & 86.4 \\
\hline & 3 & 9.1 & 9.5 & 107.5 & 97.4 & 95.8 & 95.6 \\
\hline & 400 & 7.9 & 3.7 & 101.0 & 106.1 & 95.3 & 99.4 \\
\hline \multirow[t]{3}{*}{ Heart } & 2500 & 5.8 & 4.4 & 98.7 & 95.2 & 96.5 & 89.4 \\
\hline & 3 & 13.4 & 10.1 & 91.3 & 102.9 & 98.8 & 98.6 \\
\hline & 400 & 6.2 & 6.0 & 107.2 & 96.0 & 94.3 & 92.3 \\
\hline \multirow[t]{3}{*}{ Lung } & 2500 & 6.8 & 7.7 & 99.1 & 94.5 & 89.9 & 94.6 \\
\hline & 3 & 7.7 & 12.2 & 91.5 & 110.9 & 85.8 & 94.7 \\
\hline & 400 & 9.9 & 5.4 & 101.5 & 104.4 & 92.3 & 92.9 \\
\hline \multirow[t]{3}{*}{ Spleen } & 2500 & 2.7 & 4.4 & 105.0 & 103.6 & 95.6 & 93.4 \\
\hline & 3 & 12.1 & 7.2 & 92.9 & 89.6 & 86.6 & 91.2 \\
\hline & 400 & 9.6 & 5.7 & 104.6 & 97.4 & 85.8 & 89.6 \\
\hline \multirow[t]{2}{*}{ Kidney } & 2500 & 3.5 & 3.1 & 97.0 & 99.9 & 86.6 & 94.5 \\
\hline & 3 & 8.6 & 11.9 & 102.2 & 94.8 & 87.5 & 88.7 \\
\hline \multirow{2}{*}{ Brain } & 400 & 3.7 & 4.4 & 110.0 & 93.1 & 88.9 & 97.1 \\
\hline & 2500 & 3.0 & 5.3 & 105.0 & 104.6 & 87.3 & 95.5 \\
\hline
\end{tabular}

LLOQ of panasenoside in plasma was $2 \mathrm{ng} / \mathrm{mL}$. The precision and accuracy were $13.5 \%$ and $88.5 \%$ at LLOQ, respectively.

Linear regressions were fitted over the range of $2-3000 \mathrm{ng} / \mathrm{mL}$ for panasenoside in mouse tissue. The calibration curve was $y=0.012663 x-0.004953, r=0.9978$ for heart; $y=0.005746 x-$ $0.001557, r=0.9978$ for liver; $y=0.005191 x-0.003484$, $r=0.9957$ for spleen; $y=0.010151 x+0.005098, r=0.9989$ for lung; $y=0.002603 x-0.001299, r=0.9966$ for kidney; and $y=0.005523 x-0.004665, r=0.9983$ for brain. The LLOQ of panasenoside in tissues was $2 \mathrm{ng} / \mathrm{mL}$. The precision at LLOQ was between $8.2 \%$ and $17.5 \%$, and accuracy was between $83.6 \%$ and $117.4 \%$, respectively.

Precision, accuracy and recovery. The inter-day and intraday precision at each QC level was $14 \%$ or less and $13 \%$ or less, respectively, while the accuracy was between $89.6 \%$ and
$110.9 \%$ (Table 1). Mean recoveries ranged from $84.2 \%$ to $94.6 \%$ in rat plasma and from $84.3 \%$ to $99.4 \%$ in mouse tissues. The recovery of the IS $(50 \mathrm{ng} / \mathrm{mL})$ was $85.8 \%$ in rat plasma and $82.7 \%$ in mouse liver.

Stability of Rat Plasma and Mouse Liver. The panasenoside in rat plasma and mouse liver was stable under short-term room temperature, freeze-thaw cycling, and long-term (20 days) storage conditions, as the bias in concentrations was within $\pm 12 \%$ of their nominal values, and precision was less than $12 \%$ (Table 2).

Pharmacokinetic Study. The main pharmacokinetic parameters were listed in Table 3 , based on non-compartment model analysis. The plasma concentration-time curves after intravenous ( 2 and $10 \mathrm{mg} / \mathrm{kg}$ ) administration of panasenoside in rats were shown in Figure 5. The $\mathrm{AUC}_{(0-t)}$ was $160.8 \pm 13.0$ and

Table 2. Stability of panasenoside and IS in rat plasma and mouse liver under various storage conditions $(n=3)$

\begin{tabular}{|c|c|c|c|c|c|c|c|c|c|}
\hline \multirow[t]{2}{*}{ Sample } & \multirow{2}{*}{$\begin{array}{l}\text { Concentration } \\
(\mathrm{ng} / \mathrm{mL})\end{array}$} & \multicolumn{2}{|c|}{ Ambient, $2 \mathrm{~h}$} & \multicolumn{2}{|c|}{$-20{ }^{\circ} \mathrm{C}, 20$ days } & \multicolumn{2}{|c|}{3 Freeze-thaw } & \multicolumn{2}{|c|}{ Autosampler ambient, $12 \mathrm{~h}$} \\
\hline & & Precision (\%) & Accuracy $(\%)$ & Precision (\%) & Accuracy $(\%)$ & Precision (\%) & Accuracy $(\%)$ & Precision (\%) & $\overline{\text { Accuracy }(\%)}$ \\
\hline \multirow[t]{4}{*}{ Plasma } & 3 & 8.0 & 97.2 & 9.3 & 104.2 & 10.7 & 98.3 & 3.8 & 107.2 \\
\hline & 250 & 8.4 & 107.8 & 6.3 & 94.0 & 8.0 & 113.0 & 3.4 & 102.0 \\
\hline & 1800 & 1.3 & 100.8 & 3.4 & 96.8 & 8.0 & 87.9 & 4.2 & 96.1 \\
\hline & 50 (IS) & 2.8 & 99.3 & 10.3 & 103.8 & 3.6 & 95.1 & 2.3 & 99.8 \\
\hline \multirow[t]{4}{*}{ Liver } & 3 & 4.1 & 95.6 & 7.7 & 110.2 & 10.9 & 110.2 & 5.7 & 100.7 \\
\hline & 400 & 7.8 & 107.1 & 6.2 & 105.5 & 9.0 & 108.2 & 4.1 & 103.0 \\
\hline & 2500 & 9.3 & 93.2 & 6.0 & 93.9 & 6.8 & 93.1 & 3.8 & 97.5 \\
\hline & 50 (IS) & 5.2 & 102.5 & 8.4 & 92.7 & 5.0 & 93.7 & 2.3 & 102.5 \\
\hline
\end{tabular}


Table 3. Main pharmacokinetic parameters after intravenous administration of panasenoside in rats $(n=6)$

\begin{tabular}{lccc}
\hline Parameters & Unit & $2 \mathrm{mg} / \mathrm{kg}$ & $10 \mathrm{mg} / \mathrm{kg}$ \\
\hline $\mathrm{AUC}_{(0-t)}$ & $\mathrm{ng} / \mathrm{mL}^{*} \mathrm{~h}$ & $160.8 \pm 13.0$ & $404.9 \pm 78.0$ \\
$\mathrm{AUC}_{(0-\infty)}$ & $\mathrm{ng} / \mathrm{mL} * \mathrm{~h}$ & $206.2 \pm 41.5$ & $470.8 \pm 43.8$ \\
$\mathrm{MRT}_{(0-\mathrm{t})}$ & $\mathrm{h}$ & $1.8 \pm 0.1$ & $1.4 \pm 0.3$ \\
$\mathrm{MRT}_{(0-\infty)}$ & $\mathrm{h}$ & $3.7 \pm 1.3$ & $3.4 \pm 1.6$ \\
$t_{1 / 2}$ & $\mathrm{~h}$ & $3.2 \pm 1.2$ & $4.6 \pm 1.7$ \\
$\mathrm{CL}$ (clearance) & $\mathrm{L} / \mathrm{h} / \mathrm{kg}$ & $10.0 \pm 2.0$ & $21.4 \pm 2.0$ \\
$V$ & $\mathrm{~L} / \mathrm{kg}$ & $44.4 \pm 8.0$ & $143.4 \pm 61.7$ \\
$C_{\max }$ & $\mathrm{ng} / \mathrm{mL}$ & $170.0 \pm 49.2$ & $961.7 \pm 409.8$ \\
\hline
\end{tabular}

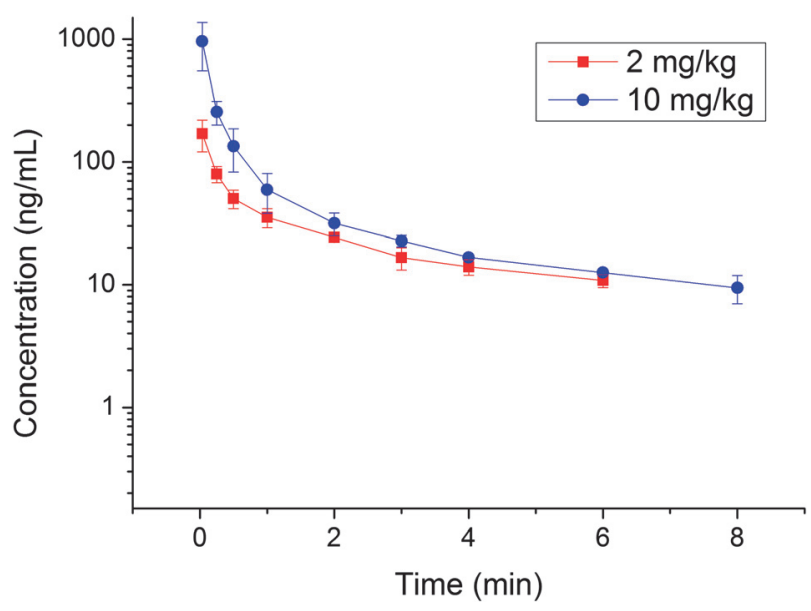

Figure 5. Mean plasma concentration time profile after intravenous ( 2 and $10 \mathrm{mg} / \mathrm{kg}$ ) administration of panasenoside in rats

$404.9 \pm 78.0 \mathrm{ng} / \mathrm{mL}^{*} \mathrm{~h} ; t_{1 / 2}, 3.2 \pm 1.2$ and $4.6 \pm 1.7 \mathrm{~h}$; and CL, $10.0 \pm 2.0$ and $21.4 \pm 2.0 \mathrm{~L} / \mathrm{h} / \mathrm{kg}$ after intravenous administration of $2 \mathrm{mg} / \mathrm{kg}$ and $10 \mathrm{mg} / \mathrm{kg}$ of panasenoside, respectively.

We have done pre-experimental oral administration of $10 \mathrm{mg} / \mathrm{kg}$ panasenoside, but the panasenoside in rat plasma is not detected, indicating that the oral absorption is poor and there is low bioavailability. The pharmacokinetics of panasenoside metabolism right after intravenous administration and the pharmacokinetic profile of panasenoside in rats were characterized for the first time, which contributed to a deeper understanding of the pharmacological features of panasenoside.

Tissue Distribution. The concentration-time curves of panasenoside in mouse plasma, heart, liver, spleen, lung, kidney, and brain after intraperitoneal administration of $15 \mathrm{mg} / \mathrm{kg}$ were shown in Figure 6.

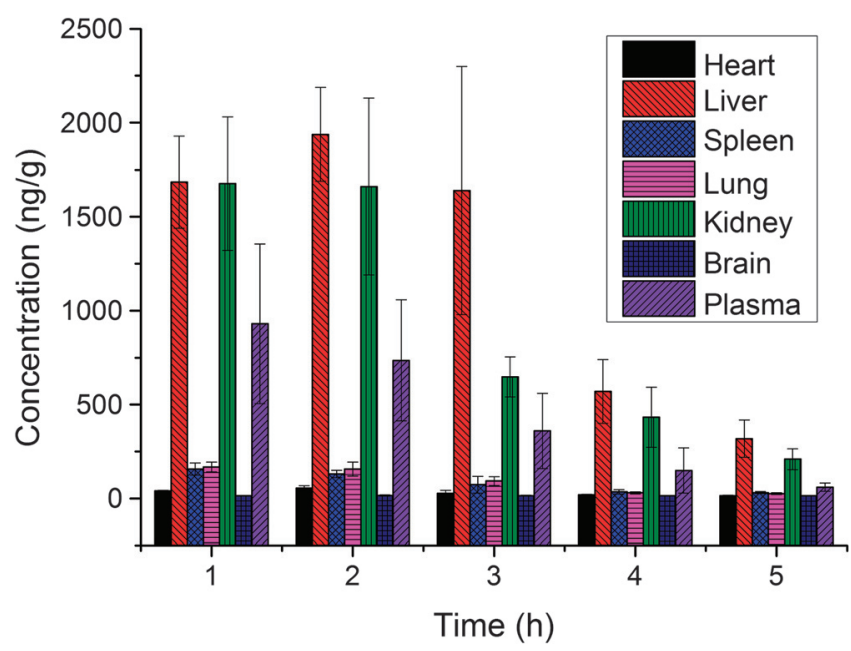

Figure 6. Mean concentration of panasenoside in tissues at different time $(0.25,0.5,2,4$, and $6 \mathrm{~h})$ after intraperitoneal administration of $20 \mathrm{mg} / \mathrm{kg}$ panasenoside in mouse
The tissue distribution results indicated that the panasenoside diffuses rapidly and widely into major organs. The level of panasenoside was highest in mouse liver, followed by kidney, lung, and spleen. The level of panasenoside in brain remains considerably low, which indicated that blood-brain barrier may effectively prevent panasenoside from moving across. The overwhelming accumulation in liver indicated that liver was responsible for the extensive metabolism of panasenoside.

\section{Conclusion}

In this study, we presented a simple and sensitive UPLCMS/MS method for the quantitation of panasenoside in $50 \mu \mathrm{L}$ of rat plasma or $50 \mathrm{mg}$ of mouse tissue with an LLOQ of $2 \mathrm{ng} / \mathrm{mL}$. We further successfully applied this UPLC-MS/MS method to pharmacokinetic study of panasenoside in rat and tissue distribution in mouse. The level of panasenoside was highest in liver, followed by kidney, lung, and spleen. The considerably low level of panasenoside in brain indicates that panasenoside may not cross through blood-brain barrier effectively.

\section{References}

1. Mi, J.; Zhang, M.; Zhang, H.; Wang, Y.; Wu, S.; Hu, P. J. Sep. Sci. 2013, 36, 593-601

2. Qiu, Y.; Lu, X.; Pang, T.; Ma, C.; Li, X.; Xu, G. J. Sep. Sci. 2008, 31, 3451-3457.

3. Wu, H.; Hoiby, N.; Yang, L.; Givskov, M.; Song, Z. J. Tradit. Chin. Med. 2014, 34, 227-233.

4. Qian, Z. M.; Lu, J.; Gao, Q. P.; Li, S. P. J. Chromatogr. A 2009, 1216 , 3825-3830.

5. Lin, W. N.; Lu, H. Y.; Lee, M. S.; Yang, S. Y.; Chen, H. J.; Chang, Y. S.; Chang, W. T. Am. J. Chin. Med. 2010, 38, 205-218.

6. Liu, M.; Su, X.; Li, G.; Zhao, G.; Zhao, L. J. Chromatogr. B Analyt. Technol. Biomed. Life Sci. 2015, 1006, 8-15.

7. Ai, Y.; Wu, Y.; Wang, F.; Ma, W.; Bian, Q.; Lee, D. Y.; Dai, R. J. Mass Spectrom. 2015, 50, 567-577.

8. Van Toi, P.; Pouplin, T.; Tho, N. D. K.; Phuong, P. N.; Chau, T. T. H.; Thuong Thuong, N. T.; Heemskerk, D.; Hien, T. T.; Thwaites, G. E. J. Chromatogr. B Analyt. Technol. Biomed. Life Sci. 2017, 1061-1062, 256-262.

9. Wijma, R. A.; Bahmany, S.; Wilms, E. B.; van Gelder, T.; Mouton, J. W.; Koch, B. C. P. J. Chromatogr. B Analyt. Technol. Biomed. Life Sci. 2017, 1061-1062, 263-269.

10. Wang, J.; Zhao, T.; Kong, J.; Peng, H.; Lv, P.; Li, J.; Cao, X.; Zhang, S. J. Chromatogr. B Analyt. Technol. Biomed. Life Sci. 2017, 1061-1062, 270-274.

11. Williams, J. S.; Donahue, S. H.; Gao, H.; Brummel, C. L. Bioanalysis 2012, 4, 1025-1037.

12. Cai, H. L.; Wang, F.; Li, H. D.; Peng, W. X.; Zhu, R. H.; Deng, Y.; Jiang, P.; Yan, M.; Hu, S. M.; Lei, S. Y.; Chen, C. J. Chromatogr. B Analyt. Technol. Biomed. Life Sci. 2014, 947-948, 156-163.

13. Du, J.; Ma, Z.; Zhang, Y.; Wang, T.; Chen, X.; Zhong, D. Bioanalysis 2014, 6, 2343-2356.

14. Liu, J.; Wang, L.; Hu, W.; Chen, X.; Zhong, D. J. Chromatogr. B Analyt. Technol. Biomed. Life Sci. 2014, 971, 35-42.

15. Ma, J.; Zhang, Q.; Wang, X. Xenobiotica 2014, 44, 849-854.

16. Wen, C.; Cai, J.; Lin, C.; Ma, J.; Wang, X. Xenobiotica 2014, 44, $743-748$.

17. Wang, X.; Pan, Y.; Jianshe, M.; Shi, S.; Zheng, X.; Xiang, Z. Xenobiotica 2014, 44, 555-561.

18. Wang, S. H.; Wu, H. Y.; Huang, X. L.; Geng, P. W.; Wen, C. C.; Ma, J.

S.; Zhou, Y. F.; Wang, X. Q. J. Chromatogr. B Analyt. Technol. Biomed. Life Sci. 2015, 990, 118-124.

19. Ma, J. S.; Wang, S. H.; Zhang, M. L.; Zhang, Q. W.; Zhou, Y. F.; Lin,

C. L.; Lin, G. Y.; Wang, X. Q. Biomed. Chromatogr. 2015, 29, 1203-1212.

20. Ma, J. S.; Wang, S. H.; Huang, X. L.; Geng, P. W.; Wen, C. C.; Zhou,

Y. F.; Yu, L. S.; Wang, X. Q. J. Pharm. Biomed. Anal. 2015, 111, 131-137.

21. Zhang, Q.; Wen, C.; Xiang, Z.; Ma, J.; Wang, X. J. Pharm. Biomed. Anal. 2014, 90, 134-138.

22. Ye, W.; Chen, R.; Sun, W; Huang, C.; Lin, X.; Dong, Y.; Wen, C.; Wang,

X. J. Chromatogr. B Analyt. Technol. Biomed. Life Sci. 2017, 1060, 144-149.

23. Wang, X. Q.; Wang, Q. Q.; Hu, Q. P.; Zhao, Y.; Chen, W. H.; Wen, C. C.; Wu, B. Lat. Am. J Pharm. 2017, 36, 1403-1407.

24. Wang, S. H.; Dong, Y. W.; Su, K.; Zhang, J.; Wang, L. Y.; Han, A. Y.; Wen, C. C.; Wang, X. Q.; He, Y. Pharm. Biol. 2017, 55, 1223-1227.

25. Jiang, Y.; Zhou, H.; Su, K.; Xu, M. Z.; Chen, B. B.; Chen, D. X.; Wen, C. C.; Wu, B.; Luo, X. H.; Wang, X. Q. Lat. Am. J. Pharm. 2016, 35, 2261-2266.

26. Lin, G. Y.; Ma, J. S.; Lin, C. L.; Hu, L. F.; Wang, X. Q. J. Liq. Chromatogr. Relat. Technol. 2014, 37, 2506-2514. 